\title{
Purification and functional characterization of protoplasts and intact vacuoles from grape cells
}

\author{
Natacha Fontes ${ }^{1,2}$, Rui Silva ${ }^{3}$, Céline Vignault ${ }^{4}$, Fatma Lecourieux ${ }^{5}$, Hernâni Gerós ${ }^{1,2^{*}}$, Serge Delrot ${ }^{5}$
}

\begin{abstract}
Background: During grape berry ripening, the vacuoles accumulate water, sugars and secondary metabolites, causing great impact in plant productivity and wine quality. However, the molecular basis of these compartmentation processes is still poorly understood. As in many species, the major bottleneck to study these aspects in grapevine is to obtain highly purified vacuoles with a good yield. The present paper describes an isolation method of protoplasts and intact vacuoles from grape berry cells and their functional characterization by transport and cytometric assays.

Findings: Protoplasts were prepared by enzymatic digestion of grape cells, and vacuoles were released and purified by a Ficoll step gradient centrifugation. The tonoplast stained strongly with the fluorescent dye FM1-43 and most vacuoles maintained an internal acidic pH, as assessed by Neutral Red. Flow cytometry analysis of vacuole samples incubated with the calcium-sensitive fluorescent probe Fluo-4 AM revealed a well-defined subpopulation of intact vacuoles. As assessed by the $\mathrm{pH}$-sensitive probe ACMA, intact vacuoles generated and maintained a pH gradient through the activity of V-ATPase and V-PPase and were able to transport $\mathrm{Ca}^{2+}$ via a proton-dependent transport system.

Conclusions: Highly pure, intact and functional protoplast and vacuole populations from grape cells were obtained with the present method, which revealed to be fast and efficient. The capacity of the vacuole population to sequester protons and accumulate $\mathrm{Ca}^{2+}$ strongly suggests the intactness and physiological integrity of these extremely fragile organelles. Grapevine protoplasts and vacuoles may be used as models for both basic research and biotechnological approaches, such as proteomics, solute uptake and compartmentation, toxicological assessments and breeding programs.
\end{abstract}

\section{Findings}

Enzymatic digestion of grape cells yields highly pure, viable and homogeneous populations of protoplasts Protoplasts were prepared from Vitis vinifera L. cells (CSB, Cabernet Sauvignon Berry). Cells were cultivated in liquid mineral medium supplemented with $2 \%(\mathrm{w} / \mathrm{v})$ sucrose. The method of Greuter and Keller [1] to isolate protoplast from Stachys sieboldii tubers was adapted for grape cells and optimized by introducing several changes, including the composition of the media, enzyme proportion and purification steps. Protoplasting was performed by enzymatic digestion of the cell walls $\left(450 \times 10^{6}\right.$ cells $)$ with $0.007 \%(\mathrm{w} / \mathrm{v})$ cellulase $\mathrm{Y}-\mathrm{C}$ and $0.0007 \%(\mathrm{w} / \mathrm{v})$ pectolyase Y-23 (Kyowa chemical

\footnotetext{
* Correspondence: geros@bio.uminho.pt
'Centro de Investigação e de Tecnologias Agro-Ambientais e Biológicas

* Correspondence: geros@bio.uminho.pt
${ }^{1}$ Centro de Investigação e de Tecnologias Agro-Ambientais e Biológicas (CITAB). Portugal
} (CTAB) Portugal

products CO., LTD) in a final volume of $50 \mathrm{ml}$. Digestion occurred in Gamborg B5 Medium supplemented with $0.4 \mathrm{M}$ sucrose, under shaking (50 rpm), at $\mathrm{pH} 5.8$ and $22^{\circ} \mathrm{C}$. Different digestion periods of 4 to $12 \mathrm{~h}$ were tested. The resulting protoplasts were gently collected and subsequently purified. Initially, protoplasts were separated by floating, at $150 \times g$ for $8 \mathrm{~min}$, and subsequently washed with the same medium. A discontinuous gradient was prepared by overlaying 1 volume of a solution containing $0.05 \mathrm{M}$ glucose, $154 \mathrm{mM} \mathrm{NaCl}, 125 \mathrm{mM}$ $\mathrm{CaCl}_{2}$ and $5 \mathrm{mM} \mathrm{KCl}, \mathrm{pH} 5.8$, on the protoplast suspension, followed by centrifugation at $150 \times g$ for $8 \mathrm{~min}$. Protoplasts were recovered from the interface of the gradient, resuspended in 3 volumes of the glucose-containing medium and sedimented for $8 \mathrm{~min}$ at $150 \times \mathrm{g}$. The pellet was washed in $0.4 \mathrm{M}$ mannitol, $15 \mathrm{mM}$ $\mathrm{MgCl}_{2}, 5 \mathrm{mM}$ Mes, pH 5.8, resuspended in the same 
medium and stored at $4^{\circ} \mathrm{C}$. Protoplasts were counted in a Malassez chamber under the light microscope. A protoplast yield of $13 \%$ was obtained as a result of a $12 \mathrm{~h}$ digestion protocol, decreasing approximately to $6 \%$ when the digestion lasted $4 \mathrm{~h}$.

The viability of the protoplasts was tested with the fluorescent dye fluorescein diacetate (FDA). The intact plasma membrane is permeable to FDA, and FDA is converted into a green fluorescent dye, fluorescein, by internal esterases, displaying a green fluorescence in viable cells [2]. Figure 1 depicts a typical protoplast population labelled with FDA observed under UV light (epifluorescence, A). Comparison of the epifluorescence light with the visible light images (results not shown) showed that most protoplasts remained viable immediately after isolation, displaying an intense green fluorescence, regardless of the duration of the digestion step (4 or $12 \mathrm{~h}$ ). However, when a $4 \mathrm{~h}$-digestion protocol was used, the viability was always higher, reaching $100 \%$ in some cases. The same conclusions were achieved after flow cytometry analysis, as described below.

Flow cytometry analysis requires that microscopical biological particles be in suspension. It allows the simultaneous quantification of multiple fluorescence emissions in the same cell or biological particle, and scattered light related to morphology [3]. Therefore, individual cells or sub-cellular particles from heterogeneous subpopulations can be physically isolated on the basis of their fluorescence or light scatter properties [4]. In the present work, flow cytometry has been exploited in order to characterize the protoplast and vacuole samples and to individualize the subpopulations, allowing conclusions about the purity of each fraction. Flow cytometric analysis was performed in an Epics ${ }^{\bullet}$ XLTM (Beckman Coulter) flow cytometer equipped with an argon-ion laser emitting a $488 \mathrm{~nm}$ beam at $15 \mathrm{~mW}$. Green fluorescence was collected through a $488 \mathrm{~nm}$ blocking filter, a $550 \mathrm{~nm}$ long-pass dichroic and a 525 $\mathrm{nm}$ band-pass filter. For each sample, 20,000 protoplasts and 20,000 vacuoles were analysed at low flow rate. An acquisition protocol was defined to measure forward scatter (FS), side scatter (SS) and green fluorescence (FL1) on a four decades logarithmic scale. Data were analysed by WinMDI 2.8 software. The analysis of the biparametric histograms, plotting log SS against log FS, revealed some heterogeneity in both relative complexity and size of the protoplast population (Figure 1B). However, the subpopulation of protoplasts can be easily identified, since it easily stains well with FDA (gated region $\mathrm{P}$ ). Above and to the right of this region, there is also a subpopulation that probably consists of protoplast aggregates. The subpopulations with the lowest scatter (below and to the left of region P) correspond mainly to submicroscopic particles - as some cell debris and cell wall residues - of relative low complexity and size, which were co-purified with the protoplasts. Figure 1C depicts the overlay of the green fluorescence and autofluorescence histograms of the gated region P. Quantification of the percentage of FDA positive stained cells indicates that the protoplasts population exhibits a high percentage of viability. These findings were previously summarized in the book chapter by Papadakis et al. [5]. The lysis of grape protoplasts yields highly pure and intact vacuoles

Vacuoles were released upon the protoplast osmotic lysis at a relatively high temperature and were purified by a Ficoll step gradient centrifugation. The methodology was adapted from the protocol used to obtain vacuoles from Arabidopsis protoplasts [6]. The protoplast suspension was added to 2.5 volumes of the prewarmed $\left(37-45^{\circ} \mathrm{C}\right)$ lysis buffer, a solution with reduced osmotic strength containing $0.2 \mathrm{M}$ mannitol, 10\% Ficoll (w/v), 15 mM EDTA, 10 mM MOPS, pH 8.0, supplemented with $0.1 \%$ BSA and $2 \mathrm{mM} \mathrm{DTT}$, resulting in the release of intact vacuoles. The vacuoles were collected from the vacuole buffer layer after a one-step Ficoll
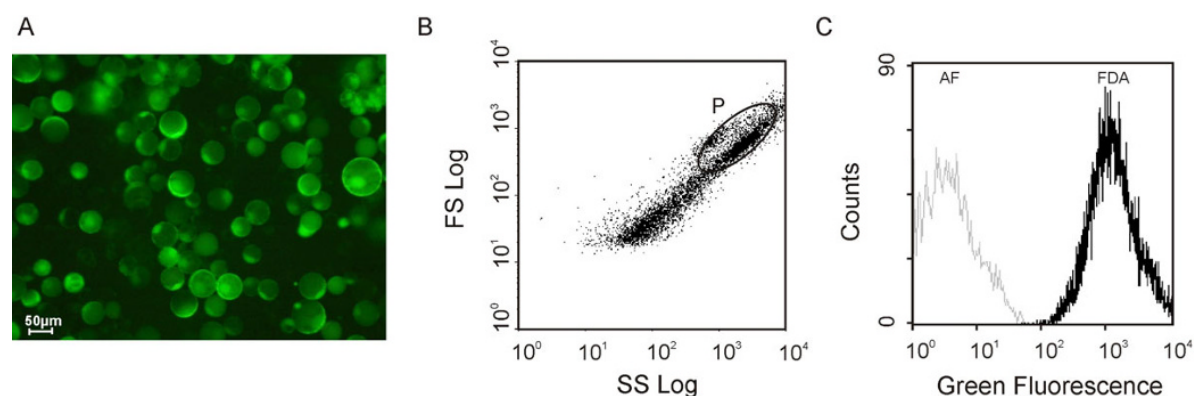

Figure 1 Microscopical and flow cytometric analysis of a protoplast population purified from grape cells. Protoplasts were labelled with FDA and observed under UV light (epifluorescence, A). Flow cytometric analysis of the protoplast population labelled with FDA: scattergram for grape cells protoplasts after FDA staining (B) and overlay of green fluorescence and autofluorescence histograms of the same protoplast suspension of gated region $P(C)$. 
gradient centrifugation of $15 \mathrm{~min}$ at $1000 \times \mathrm{g}$. The discontinuous gradient was optimized as follows: one layer of the lysis mixture (10\% Ficoll, w/v), one layer of $3.0 \%$ Ficoll $(w / v)$ and one layer of vacuole buffer containing $0.5 \mathrm{M}$ mannitol, $10 \mathrm{mM}$ MOPS, $\mathrm{pH} 7.5$ and a protease inhibitor cocktail (Complete, Roche Applied Science, Germany), in the proportion of 7:3:1 volumes. The 3.0\% Ficoll solution was prepared by diluting the lysis buffer with vacuole buffer. The vacuoles were counted on a Malassez chamber under the light microscope. In a typical fractionation procedure, an average amount of $4.0 \times$ $10^{6}$ vacuoles was obtained, corresponding to about $12 \%$ of the total number of protoplasts (purified by a $12-\mathrm{h}$ digestion protocol) subjected to lysis. Since the yield of intact vacuoles was always higher when protoplasts were isolated by a 12-h digestion protocol (not shown), this digestion duration was used in all subsequent experiments. Cytosolic glucose-6-phosphatase was used as a marker enzyme to monitor vacuole purification [7]. The specific activities of the protoplast preparation and vacuole preparation were 715 and $14.6\left(\mathrm{nmol} \mathrm{min}{ }^{-1} \mathrm{mg}\right.$ $\left.\operatorname{prot}^{-1}\right)$, respectively. Only $2 \%$ of the marker enzyme was recovered in the vacuolar fraction, indicating that this sample was strongly depleted in protoplasts and cytosolic contaminations. This conclusion was further supported by microscopic observation and flow cytometry analysis.

To visualize the vacuoles with the fluorescence microscope, the styryl dye FM 1-43 was used as described earlier [8]. This fluorescent probe exhibits weak fluorescence in aqueous medium, but shines brightly when inserted into membranes [9]. Incubation resulted in a strong staining of the tonoplast (Figure 2A), demonstrating the intactness of these extremely fragile organelles. Vacuole preparations do not contain just "naked" vacuoles, and some vacuoles seem to be contaminated with cytoplasmic remnants. Such "impure vacuoles" were easily identified under the light or fluorescence microscope after FDA labelling, as reported before [10], as well as by incubation with the styryl dye FM 1-43 (Figure 2A, inset). This figure suggests that several structures belonging to the "vacuolar apparatus" (i.e., vacuoles and those membranous bodies that are either committed to become vacuolar or that have immediately completed a vacuolar function) remained attached to the central vacuole after protoplast lysis. The virtual absence of intact protoplasts in the vacuole preparations was confirmed by the lack of labelling by FDA that only stains the cytoplasm.

Most of the intact vacuoles, ranging in size from 10 to $50 \mu \mathrm{m}$, maintained an internal acidic $\mathrm{pH}$ and exhibited a red colour after being labelled with Neutral Red, a lipophilic phenazine dye (Sigma-Aldrich), in spite of their resuspension in a buffer at pH 7.5 (Figure 2B).
This acidity was relatively stable and was not completely abolished by the incubation with $100 \mu \mathrm{M}$ CCCP. This may be due to the buffering capacity of organic acids accumulated in the vacuoles, but we must not discard the fact that higher protonophore concentrations could promote red colour dissipation. However, $2.5 \mathrm{mM}$ $\mathrm{NH}_{4} \mathrm{Cl}$ almost completely abolished the $\mathrm{pH}$ gradient across the majority of the vacuoles.

The flow cytometry analysis of vacuole samples is depicted in Figure 3A and 3B. The scattergram shows a well-defined subpopulation in the centre of the histogram, corresponding to the vacuole population (gated region $\mathrm{V}$ ). After an incubation period of $15 \mathrm{~min}$ at room temperature with the calcium probe Fluo-4 AM (Molecular Probes, Eugene, OR, USA), the fluorescence of the gated region $\mathrm{V}$ increased (Figure $3 \mathrm{~B}$ ), indicating the vacuole ability to accumulate calcium. The use of flow cytometry to analyze the functional properties of isolated subcellular particles is less frequent than its application in whole cell studies. However, most current instruments are sensitive enough for subcellular analyses. In the present work, flow cytometric analysis allowed us to identify well-defined and viable subpopulations of protoplasts and vacuoles, based on viability (FDA) and calcium content (Fluo-4 AM), respectively (Figure 1 and 3). These findings regarding vacuole characterization by microscopy and flow cytometry analysis were previously summarized in the book chapter by Papadakis et al. [5]. So far, only spinach chloroplasts [11] and rice protoplasts [12] have been studied by flow cytometry. The present results open new perspectives for future work concerning the study of calcium transport across the tonoplast with calcium sensitive fluorescent probes and flow cytometry analysis.

Intact vacuoles from grape cells are physiologically active organelles

Monitoring the transmembrane proton gradient in intact vacuoles is a proper approach to study the mechanisms of vacuolar acidification, because intact vacuoles are physiologically closer to the in vivo plant system than tonoplast vesicles. The low $\mathrm{pH}$ of the vacuole of fruit cells is the result of two processes: 1) pumping protons across the tonoplast, which directly results in a drop of vacuolar $\mathrm{pH}$, and 2) synthesis and accumulation of organic acids in the vacuolar sap [13]. For proton-pumping measurements, intact vacuoles were labelled with ACMA (9-amino-6-chloro-2-methoxyacridine), a highly sensitive $\mathrm{pH}$-dependent fluorescent dye. The fluorescence quenching of ACMA was measured using a Perkin-Elmer LS-50 [14,15]. Vacuoles (between $1.0 \times 10^{4}$ and $1 \times 10^{5}$ ) were added to the assay cuvette $(2.0 \mathrm{ml})$, containing $100 \mathrm{mM} \mathrm{KCl,} 2 \mathrm{mM}$ $\mathrm{MgCl}_{2}, 0.1 \%$ BSA (w/v), $10 \mathrm{mM}$ MOPS-Tris pH 7.2 and $2 \mu \mathrm{M}$ ACMA. The optimal concentration of $\mathrm{Mg}^{2+}$ in 


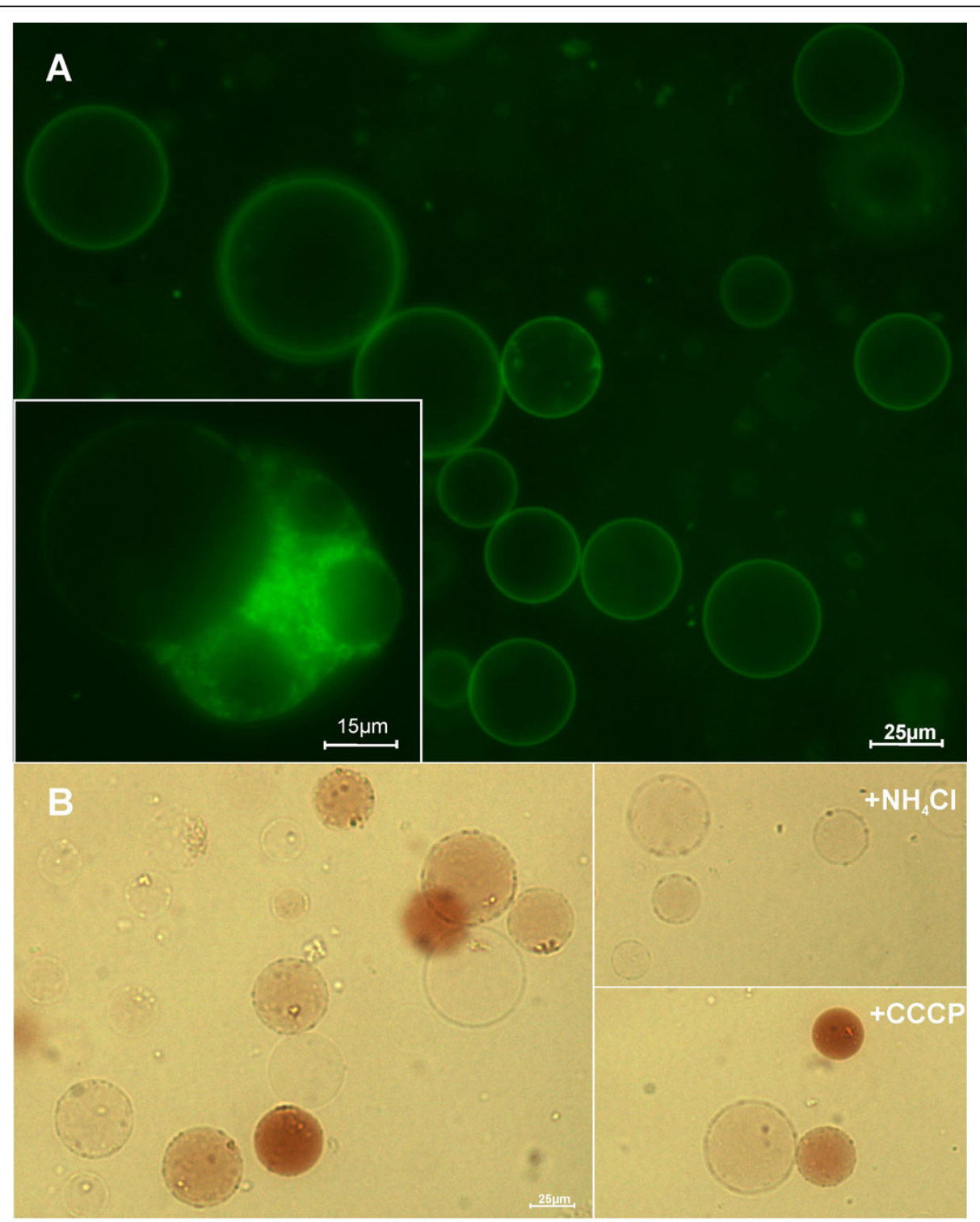

Figure 2 Microscopic characterization of intact vacuoles purified from grape protoplasts. Intact vacuoles, purified after protoplast lysis, labelled with the fluorescent membrane marker FM1-43 (A; inset: membranous bodies attached to the central vacuole forming an "impure vacuole") observed under the fluorescence microscope. Intact vacuoles labelled with neutral red in the absence and in the presence of $2.5 \mathrm{mM}$ $\mathrm{NH}_{4} \mathrm{Cl}$ and $25 \mu \mathrm{M}$ CCCP (B).

the assay medium was previously adjusted taking into account that the cation forms insoluble complexes with $\mathrm{PP}$, and then changing $\mathrm{PP}_{\mathrm{i}} / \mathrm{Mg}^{2+}$ ratio modifies the $\mathrm{H}^{+}$ pumping activity of V-PPase (Maeshima, M., personal communication). Figure 4 shows the PPi-dependent and ATP-dependent $\mathrm{H}^{+}$pumping activities across the membrane of intact vacuoles from grape cells, as measured by the fluorescence quenching of ACMA. Both $\mathrm{NH}_{4} \mathrm{Cl}$ and $\mathrm{CCCP}$ induced a prompt recovery of ACMA fluorescence, demonstrating the generation of a $\mathrm{pH}$ gradient. In this biological system, the V-PPase seems to be the main tonoplast proton pump, generating a $\mathrm{pH}$ gradient 1.4-fold greater than the V-ATPase, counting with 170 times less substrate concentration: the $V_{\max }$ value for the V-PPase proton pumping was $4.3 \times 10^{-5} \% \Delta \mathrm{F} \mathrm{min}^{-1}$ vac $^{-1}$, while the $V_{\max }$ for V-ATPase was $3.1 \times 10^{-5} \% \Delta \mathrm{F}$ $\mathrm{min}^{-1} \mathrm{vac}^{-1}$. Indeed, the $K_{\mathrm{m}}$ of V-PPase proton pumping was determined to be $2.0 \mu \mathrm{MPPi}$, while the $K_{\mathrm{m}}$ for the V-ATPase was $340 \mu \mathrm{M}$ ATP.

The ability of $\mathrm{CaCl}_{2}$ to dissipate a pre-established $\Delta$ $\mathrm{pH}$ gradient across the tonoplast was used to assess the involvement of a $\mathrm{Ca}^{2+} / \mathrm{H}^{+}$antiport system. The addition of $\mathrm{CaCl}_{2}$ to energized intact vacuoles through the activation of V-PPase resulted in an immediate dissipation of 
A

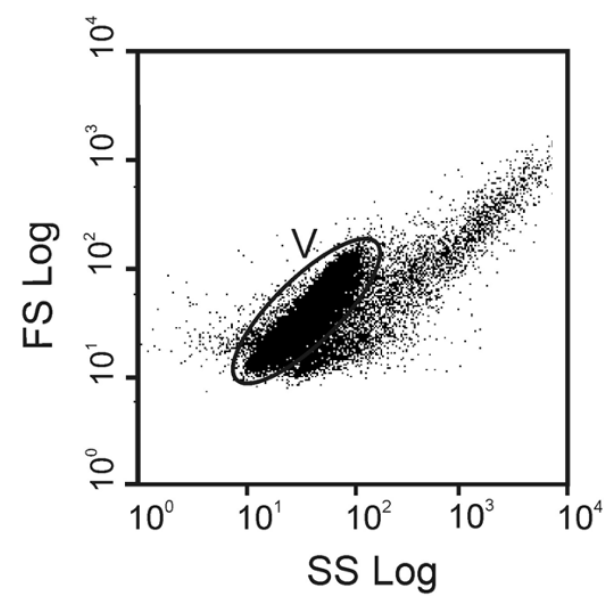

B

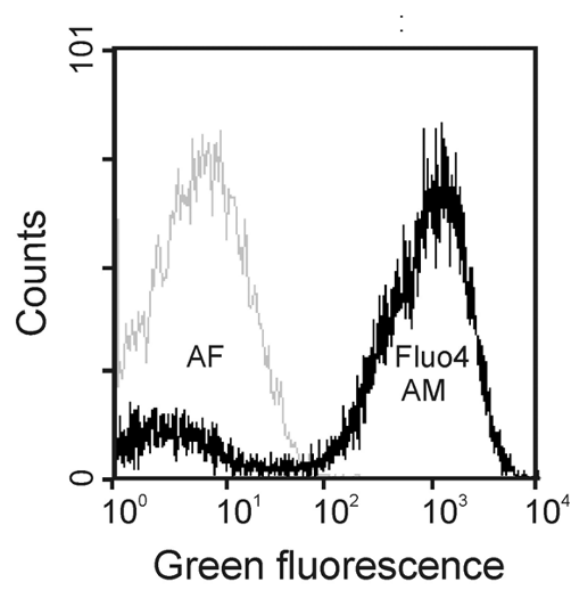

Figure 3 Flow cytometric analysis of a vacuole population purified from grape protoplasts. Scattergram (dot plot) of a vacuole suspension after Fluo-4 AM staining (A) and overlay of green fluorescence histograms of stained and autofluorescence of vacuole suspension for gated region $\vee(B)$.

the proton gradient (Figure 5A). Initial velocities of fluorescence recovery after $\mathrm{Ca}^{2+}$ addition followed a Michaelis-Menten kinetics, and a $K_{\mathrm{m}}=0.4 \mathrm{mM}$ and a $V_{\max }=1.68 \times 10^{-4} \% \Delta \mathrm{F} \mathrm{m^{-1 }} \mathrm{vac}^{-1}$ were estimated (Figure $5 \mathrm{~A}$, inset $)$. A vacuole sample $(100 \mu \mathrm{l})$ was also labelled with $0.5 \mu \mathrm{M}$ of the calcium probe Fluo-4 AM, for $15 \mathrm{~min}$ at room temperature, prior to observation under the fluorescent microscope. The high fluorescence observed was substantially decreased after the addition of $300 \mu \mathrm{M}$ calcymicin (Figure 5B). These data, together with those from flow cytometry analysis, suggest that a functional $\mathrm{Ca}^{2+} / \mathrm{H}^{+}$antiporter is working in the purified vacuoles from grape cells, which is likely to contribute to the accumulation of $\mathrm{Ca}^{2+}$.

Above results show that two distinct primary proton pumps, the vacuolar ATPase and the vacuolar inorganic pyrophosphatase (V-PPase), generate a proton electromotive force, which, in turn, allow the secondary active transport of several compounds that are accumulated in the vacuole, as it has been shown for $\mathrm{Ca}^{2+}$ uptake. However, we must not ignore that the long digestion period used to purify the protoplasts can affect both the vacuolar contents and the activity of the transporter proteins. The predominant activity of the $\mathrm{V}$ PPase compared to that of V-ATPase in intact vacuoles (Figure 4) is in agreement with the earlier results [14,16-18]. The capacity of the vacuole population to sequester protons strongly suggests the intactness and integrity of these extremely fragile organelles.

\section{Conclusions}

Structural studies [19-21] and, more recently, proteomic analysis [22-26] have elucidated some aspects of vacuole function and biogenesis, and have generated an
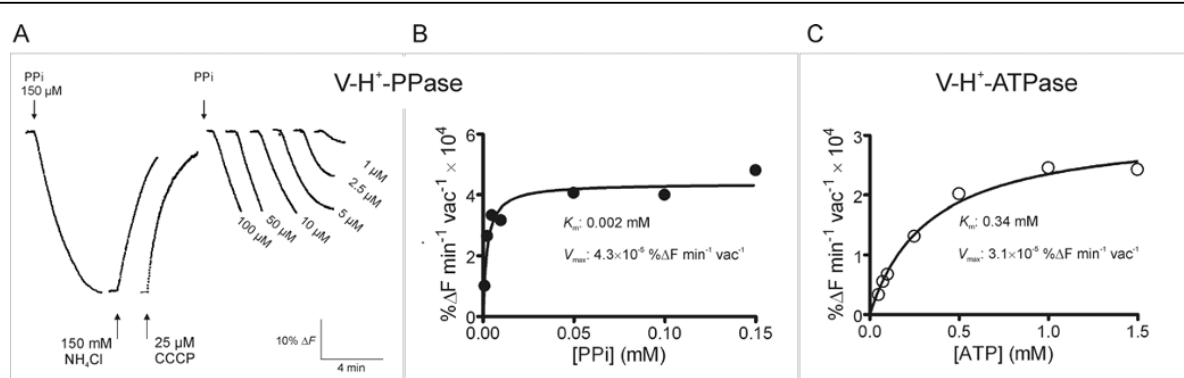

Figure 4 Proton pumping activity in intact vacuoles purified from grape protoplasts. The accumulation of protons was determined by measuring the fluorescence quenching of ACMA $[14,15]$ in $2 \times 10^{5}$ vacuoles. Typical fluorescence signals of the initial velocities of proton pumping by $\mathrm{V}-\mathrm{H}^{+}$-PPase after addition of 0.1 to $150 \mu \mathrm{M} \mathrm{PPi}(\mathrm{A})$ and the corresponding Michaelis-Menten plot (B). Michaelis-Menten plot of the initial velocities of proton pumping by $\mathrm{V}-\mathrm{H}^{+}$-ATPase as a function of ATP concentration $(0.05$ to $1.5 \mathrm{mM})$ (C). The results presented in $B$ and $\mathrm{C}$ show the average values of two independent experiments. 


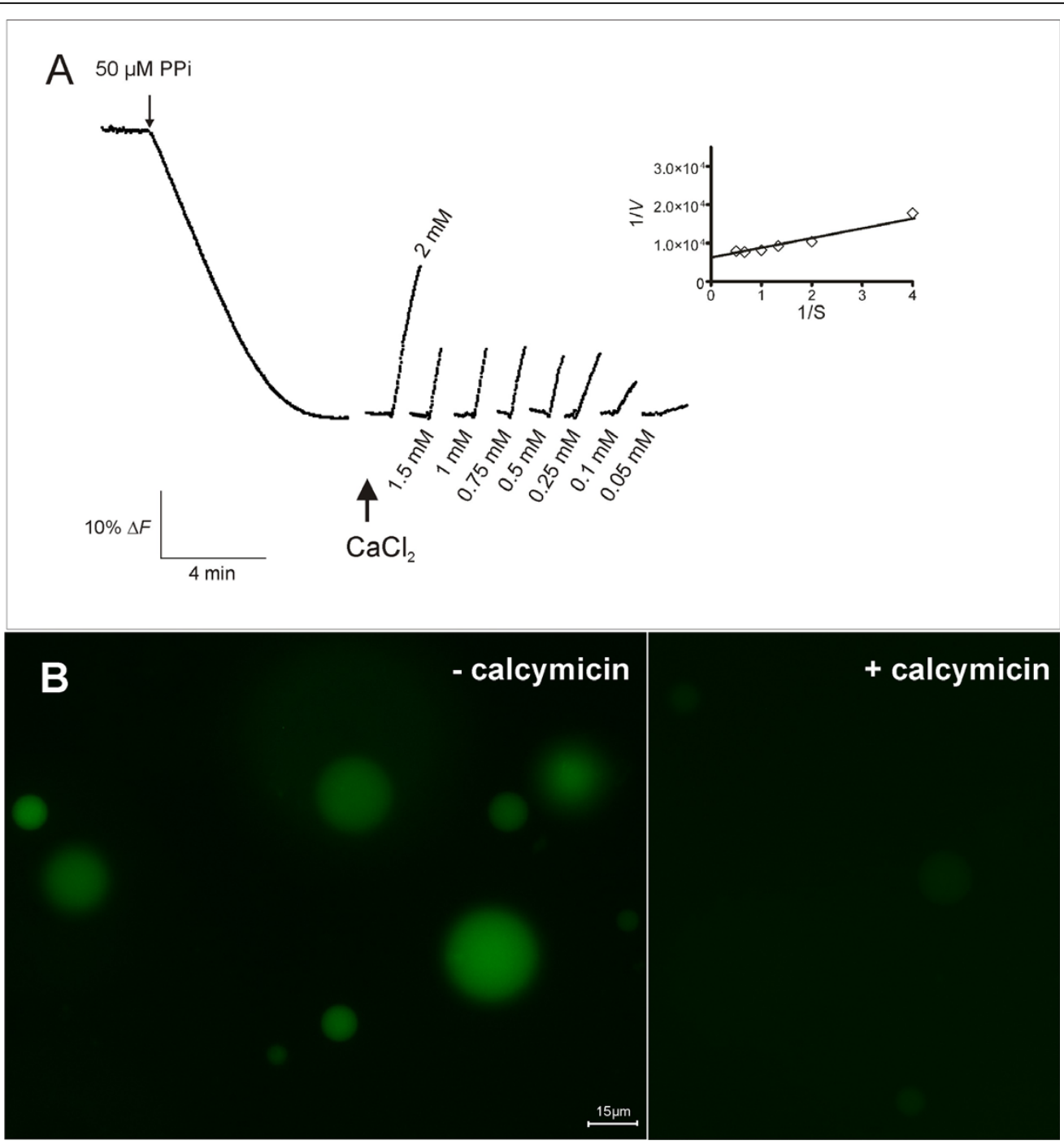

Figure 5 Study of the involvement of $\mathrm{H}^{+}$-dependent $\mathrm{Ca}^{2}$ uptake in intact vacuoles purified from grape protoplasts. Effect of $\mathrm{Ca}^{2+}$ on the pre-formed transmembrane proton gradient (A). Inset: Lineweaver-burk plot of the initial velocities of fluorescence recovery as function of $\mathrm{Ca}^{2+}$ concentration. The fluorescence signals shown are representative of at least three independent experiments. Intact vacuoles labelled with the calcium fluorescent probe Fluo-4 AM in the absence and in the presence of $300 \mu \mathrm{M}$ calcymicin, observed under the fluorescence microscope (B).

unpredicted interest in the purification of this extremely fragile organelle. During the ripening of fleshy fruits, the vacuoles accumulate water, sugars and secondary metabolites $[13,27,28]$. In spite of its importance for crop yield and quality, the molecular basis of these compartmentation processes is still poorly understood for grapevine. As in many species, the major bottleneck to study these aspects in grapevine is to obtain highly purified vacuoles with a good yield. This work describes the preparation of intact and viable vacuoles from grape cells suspensions, so as to demonstrate their feasibility as a model system to study the mechanisms underlying vacuolar compartmentation. A fast and efficient method has been developed to isolate highly pure and intact protoplast and vacuoles from grape suspension-cultured cells. Protoplasts and vacuoles may be used as models for both basic research and biotechnological approaches, such as proteomics, solute uptake and compartmentation, toxicological assessments and grapevine breeding programs.

\section{Acknowledgements}

This work was supported in part by the Fundação para a Ciência e a Tecnologia (research projects no. POCl/AGR/56378/2004 and no. PTDC/AGRALI/100636/2008; grant no. SFRH/BD/23169/2005 to N.F), the Conférence Française des Présidents d'université (CPU) and Conselho de Reitores das Universidades Portuguesas (CRUP) (Actions Intégrées Luso-Françaises - 2008/ 2009). The authors would like to thank Filomena Louro of the Scientific Editing Program of Universidade do Minho for revising the English text of 
the manuscript and Prof. Manuela Côrte-Real for her support and expert assistance on flow cytometry experiments, as well as the COST 858 network on viticulture for facilitating our exchanges.

\section{Author details}

${ }^{1}$ Centro de Investigação e de Tecnologias Agro-Ambientais e Biológicas (CITAB). Portugal. ${ }^{2}$ Departamento de Biologia, Universidade do Minho, Campus de Gualtar, 4710-057 Braga, Portugal. ${ }^{3}$ Centro de Biologia Molecular e Ambiental, Departamento de Biologia, Universidade do Minho, Braga, Portugal. ${ }^{4}$ Laboratoire de Physiologie Moléculaire du Transport des Sucres chez les Végétaux, Université de Poitiers, Poitiers, France. ${ }^{5}$ UMR 1287 Ecophysiology and Grape Functional Genomics, University of Bordeaux, INRA, Institut des Sciences de la Vigne et du Vin, Domaine de la Grande Ferrade, 210 chemin de Leysotte, 33883 Villenave d'Ornon, France.

\section{Authors' contributions}

NF carried out the experiments reported in the main manuscript, performed data processing and statistical analysis and participated in amending the draft. RS assisted flow cytometric analysis. FL and CV contributed to the optimization of the protoplast purification procedure. $\mathrm{HG}$ and SD conceived the study and wrote the manuscript. All the authors approved the final version.

\section{Competing interests}

The authors declare that they have no competing interests.

Received: 7 November 2009

Accepted: 22 January 2010 Published: 22 January 2010

\section{References}

1. Greutert $\mathrm{H}$, Keller F: Further evidence for stachyose and sucrose $/ \mathrm{H}^{+}$ antiporters on the tonoplast of Japanese Artichoke (Stachys sieboldii) tubers. Plant Physiol 1993, 101:1317-1322.

2. Jones KH, Senft JA: An improved method to determine cell viability by simultaneous staining with fluorescein diacetate-propidium iodide. $J$ Histochem Cytochem 1985, 33:77-79.

3. O'Connor JH, Callaghan RC, Escudero M, Herrera G, Martínez A, Monteiro MC, Montolíu H: The relevance of flow cytometry for biochemical análisis. IUBMB Life 2001, 51:231-239.

4. Herrera G, Diaz L, Martinez-Romero A, Gomes A, Villamón E, Callaghan RC, $\mathrm{O}$ Connor JH: Cytomics: a multiparametric, dynamic approach to cell research. Toxicol in Vitro 2006, 21:176-182

5. Papadakis AK, Fontes N, Gerós H, Roubelakis-Angelakis KA: Progress in grapevine protoplast technology. Grapevine Molecular Physiology and Biotechnology Springer Academic Publishers; NetherlandsRoubelakisAngelakis KA, 22009.

6. Carter C, Pan S, Zouhar J, Ávila EL, Girke T, Raikhel N: The vegetative vacuole proteome of Arabidopsis thaliana reveals predicted and unexpected proteins. Plant Cell 2004, 16:3285-3303.

7. Boller T, Kend $\mathrm{H}$ : Hydrolytic enzymes in the central vacuole of plant cells. Plant Physiol 1979, 63:1123-1132.

8. Conde C, Silva P, Agasse A, Tavares RM, Delrot S, Gerós H: An Hg-sensitive channel mediates the diffusional component of glucose transport in olive cells. Biochim Biophys Acta 2007, 1768:2801-2811.

9. Betz WJ, Mao F, Smith CB: Imaging exocytosis and endocytosis. Curr Opin Neurobiol 1996, 6:365-371.

10. Admon A, Jacoby B: Assessment of cytoplasmic contaminations in isolated vacuole preparations. Plant Physiol 1980, 65:85-87.

11. Schroder WP, Petit PX: Flow cytometry of spinach chloroplasts. Determination of intactness and lectin-binding properties of the envelope and the thylakoid membranes. Plant Physiol 1992, 100:1092-1102.

12. Moudakiri O, Deming J, O'Connor JR, Cornejo MJ: Phenotypic characterization of the progenies of the rice plants derived from cryopreserved calli. Plant Physiol Reports 1999, 18:625-632.

13. Shiratake K, Martinoia E: Transporters in fruit vacuoles. Plant Biotechnology 2007, 24:127-133.

14. Queirós F, Fontes $N$, Silva P, Almeida D, Maeshima M, Gerós H, Fidalgo F: Activity of tonoplast proton pumps and $\mathrm{Na}^{+} / \mathrm{H}^{+}$exchange in potato cell cultures is modulated by salt. J Exp Bot 60(4):1363-74.
15. Façanha AR, de Meis L: Reversibility of $\mathrm{H}^{+}$-ATPase and $\mathrm{H}$ + ${ }_{-}$Pyrophosphatase in tonoplast vesicles from maize coleoptiles and seeds. Plant Physiol 1998, 116:1487-1495.

16. Nakanishi $\mathrm{Y}$, Maeshima M: Molecular cloning of vacuolar $\mathrm{H}$ ${ }^{+}$-pyrophosphatase and its developmental expression in growing hypocotyl of mung bean. Plant Physiol 1998, 116:589-597.

17. Terrier N, Deguilloux C, Sauvage FX, Martinoia E, Romieu C: Proton pumps and anion transport in Vitis vinifera: The inorganic pyrophosphatase plays a predominant role in the energization of the tonoplast. Plant Physiol Biochem 1998, 36:367-377.

18. Otoch MLO, Sobreira ACM, Aragão MEF, Orellano EG, Lima MGS, de Melo DF: Salt modulation of vacuolar $\mathrm{H}^{+}$-ATPase and $\mathrm{H}$ ${ }^{+}$-Pyrophosphatase activities in Vigna unguiculata. J Plant Physiol 2001 158:545-551.

19. Paris N, Stanley CM, Jones RL, Rogers JC: Plant cells contain two functionally distinct vacuolar compartments. Cell 1996, 85:563-572.

20. Swanson SJ, Bethke PC, Jones RL: Barley aleurone cells contain two types of vacuoles: characterization of lytic organelles by use of fluorescent probes. Plant Cell 1998, 10:685-698.

21. Park M, Kim SJ, Vitale A, Hwang I: Identification of the protein storage vacuole and protein targeting to the vacuole in leaf cells of three plant species. Plant Physiol 2004, 134:625-639.

22. Shimaoka T, Ohnishi M, Sazuka T, Mitsuhashi N, Hara-Nishimura I, Shimazaki Kl, Maeshima M, Yokota A, Tomizawa Rl, Mimura T: Isolation of intact vacuoles and proteomic analysis of tonoplast from suspensioncultured cells of Arabidopsis thaliana. Plant Cell Physiol 2004, 45:672-683.

23. Reisen D, Marty F, Leborgne-Castel N: New insights into the tonoplast architecture of plant vacuoles and vacuolar dynamics during osmotic stress. BMC Plant Biology 2005, 5:1-13

24. Endler A, Meyer S, Schelbert S, Schneider T, Weschke W, Peters SW, Keller F, Baginsky S, Martinoia E, Schmidt UG: Identification of a vacuolar sucrose transporter in Barley and Arabidopsis mesophyll cells by a tonoplast proteomic approach. Plant Physiol 2006, 141:196-207.

25. Jaquinod M, Villiers F, Kieffer-Jaquinod S, Hugouvieux V, Bruley C, Garin J, Bourguignon J: A proteomic dissection of Arabidopsis thaliana vacuoles isolated from cell culture. Mol Cell Proteomics 2007, 6:394-412.

26. Schmidt UG, Endler A, Schelbert S, Brunner A, Schnell M, Neuhaus HE, Marty-Mazars D, Marty F, Baginsky S, Martinoia E: Novel tonoplast transporters identified using a proteomic approach with vacuoles isolated from Cauliflower buds. Plant Physiol 2007, 145:216-229.

27. Conde C, Agasse A, Glissant D, Tavares RM, Gerós H, Delrot S: Pathways of glucose regulation of monosaccharide transport in grape cells. Plant Physiol 2006, 141:1563-1577.

28. Conde C, Silva P, Fontes N, Dias ACP, Tavares RM, Sousa MJ, Agasse A, Delrot $\mathrm{S}$, Gerós H: Biochemical changes throughout grape berry development and fruit and wine quality. Food 2007, 1:1-22.

doi:10.1186/1756-0500-3-19

Cite this article as: Fontes et al:: Purification and functional characterization of protoplasts and intact vacuoles from grape cells. BMC Research Notes 2010 3:19.

\section{Submit your next manuscript to BioMed Central and take full advantage of:}

- Convenient online submission

- Thorough peer review

- No space constraints or color figure charges

- Immediate publication on acceptance

- Inclusion in PubMed, CAS, Scopus and Google Scholar

- Research which is freely available for redistribution

Submit your manuscript at www.biomedcentral.com/submit
C Biomed Central 